\title{
Aprendendo diversidade e classificação botânica por meio da experiência do Herbário Digital da EFA Iêda Tanan da Silva ${ }^{1}$; Alessandra Alexandre freixo ${ }^{2}$ \\ 1. Bolsista PIBIC/CNPq, Licenciatura em Ciências Biológicas, Universidade Estadual de Feira de Santana, e-mail: ieda_tanan@hotmail.com \\ 2. Orientador, DEDU, Universidade Estadual de Feira de Santana, e-mail: aafreixo@hotmail.com
}

\section{PALAVRAS-CHAVE: Escola Família Agrícola; Ensino de Botânica; Classificação Biológica.}

\section{INTRODUÇÃO}

A botânica compõe uma das maiores áreas de conhecimento da biologia, e embora as plantas estejam presentes em nosso cotidiano de diversas formas, o ensino sobre elas encontra forte resistência quer seja pelo desinteresse do professor, como dos alunos. Assim, esse trabalho apresenta as atividades desenvolvidas na Escola Família Agrícola Avaní de Lima Cunha (EFA-Valente), por meio de oficinas que articulem o diálogo de saberes e os conhecimentos prévios dos estudantes sobre as plantas e seu modo de classificação, buscando compreender o papel do Herbário Digital na sistematização e socialização desses conhecimentos, para além do espaço escolar.

Oliveira e Freixo (2019) afirmam que atividades práticas como um herbário digital em escolas do campo podem contribuir para o aprendizado de botânica de forma significativa, pois os estudantes muitas vezes estão em contato direto com plantações em seu cotidiano. Assim, os herbários visam tornar o ensino de botânica mais lúdico e contextualizado com a realidade dos alunos.

A EFA- Valente segue a Pedagogia da Alternância como referencial teórico metodológico, em que os alunos revezam uma semana na escola e outra em casa, possibilitando além da articulação dos conhecimentos adquiridos na escola com a comunidade, a formação do sujeito do campo (TEIXEIRA; FREIXO, 2011). Além da articulação dos conhecimentos adquiridos na escola com a comunidade, visa também a valorização do diálogo entre os saberes tradicionais da comunidade e o científico evidenciando a cultura popular (TEIXEIRA; FREIXO, 2011).

\section{METODOLOGIA}

Essa pesquisa segue os pressupostos teórico-metodológicos da pesquisa-ação proposto por Barbier (2002) e teve como público alvo estudantes do $6^{\circ}$ e do $8^{\circ}$ ano do ensino fundamental. $\mathrm{O}$ trabalho foi dividido em duas etapas; primeira, acompanhamento das atividades desenvolvidas na escola e manutenção do herbário digital; segunda, realização de oficinas sobre diversidade e classificação botânica. Tal oficina foi executada em três momentos distintos: apresentação da proposta "Das Plantas que Conhecemos", nesse momento os estudantes foram estimulados a escolher, citar e desenhar uma planta, que fizesse parte ou não de seu cotidiano. No segundo encontro os estudantes realizaram classificações intuitivas com as plantas citadas na etapa anterior e 
no terceiro encontro a partir do livreto produzido com a sistematização dos resultados obtidos nas etapas anteriores, abrimos espaço para o diálogo de saberes discutindo as diferenças entre a classificação feita pela "ciência" e a que eles realizaram, promovendo o diálogo entre saberes ditos tradicionais e científicos.

A partir das atividades desenvolvidas na oficina, ampliamos o herbário digital da EFA. Para tanto, buscamos informações e curiosidades sobre cada espécie, acrescentamos informações sobre os trabalhos desenvolvidos ao longo do projeto "Observatório de Juventudes Rurais na Região Sisaleira da Bahia", oficinas que abordem temas relacionados à botânica e divulgação dos trabalhos e eventos que acontecem na escola. Para finalizar o trabalho retornamos à escola para apresentação do site para a comunidade escolar. Para análise das narrativas advindas das transcrições das gravações e dos escritos dos estudantes, utilizou-se da Análise de Conteúdo apresentada por Bardin (2004).

\section{RESULTADOS E/OU DISCUSSÃO}

O Quadro 1 apresenta as espécies que foram escolhidas pela turma do $6^{\circ}$ ano; nele observamos que tal escolha baseia-se nas plantas que estão presentes em seu cotidiano, seja em casa ou na escola, corroborando com resultados obtidos por Lima e Freixo (2012), e na forma com que aquela espécie é utilizada, seja pra alimentação humana, no uso medicinal, ou mesmo na ornamentação.

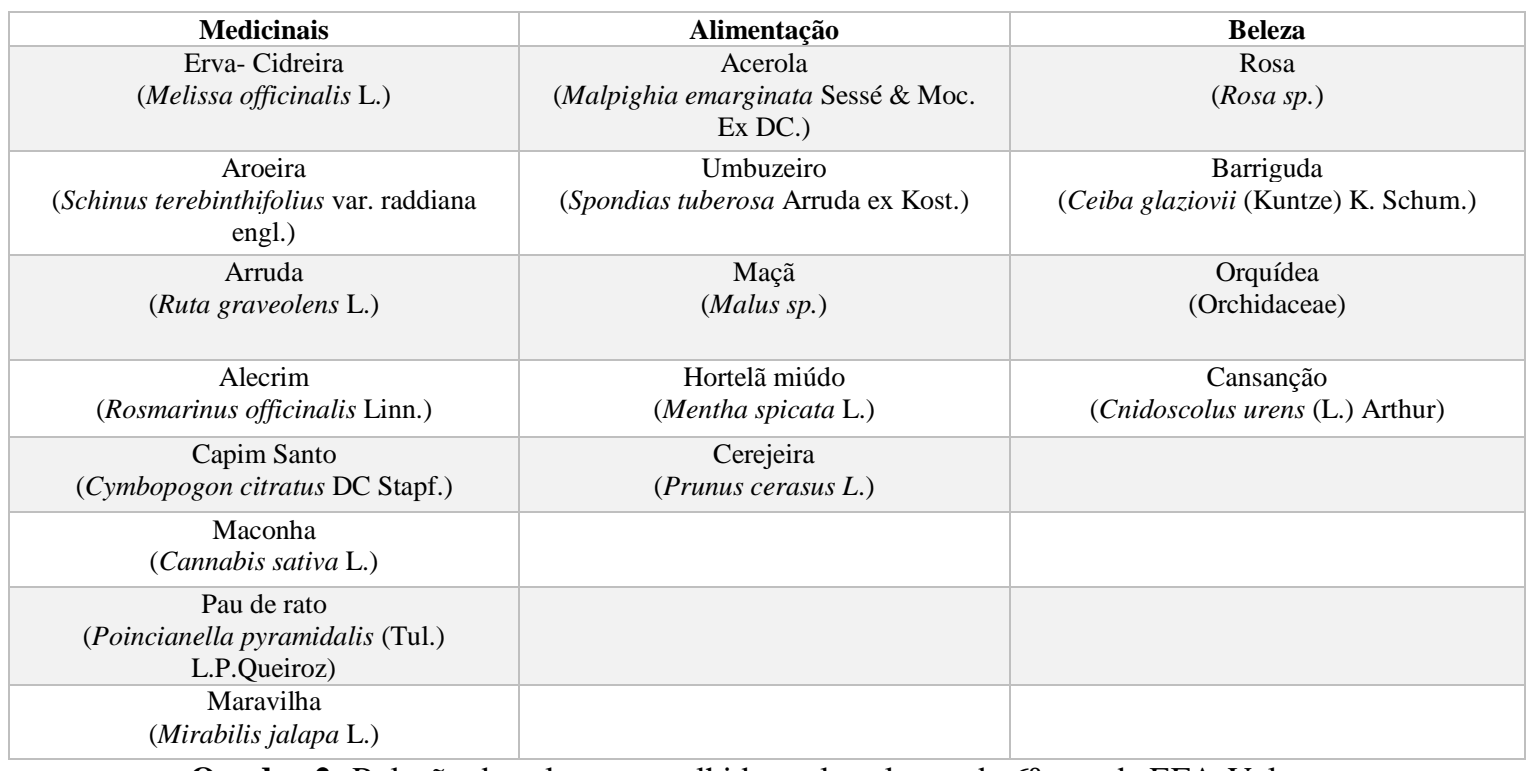

Quadro 2: Relação das plantas escolhidas pelos alunos do $6^{\circ}$ ano da EFA-Valente.

Das 17 espécies citadas pela turma, 8 foram selecionadas pelo uso medicinal, como apresentado na seguinte fala que justifica a escolha do Pau de rato (Poincianella pyramidalis (Tul.) L.P.Queiroz):

Essa planta serve para fazer chá para dor de barriga. Eu escolhi essa planta porque ela é muito importante para nossa saúde, ficar saudável e muito forte e não ter mais dor de barriga. (Alternante do $6^{\circ}$ ano)

Resultado semelhante foi encontrado por Oliveira e Freixo (2019), em que durante a coleta de plantas para confecção de um herbário digital, notaram a preferência 
dos alternantes pelas plantas medicinais e que os mesmos apresentavam um amplo conhecimento sobre sua utilização. Como apresentado no Quadro 3, os (as) alternantes do $8^{\circ}$ ano, escolheram plantas que estão relacionadas ao trabalho, diferente da percepção do $6^{\circ}$ ano.

\begin{tabular}{|c|c|c|c|}
\hline Alimentação Animal & Caatinga & Fruta & Ornamental/Bonita \\
\hline Caroá/gravatá (Neoglaziovia sp.) & $\begin{array}{l}\text { Cabeça de frade (Melocactus } \\
\text { zehntneri (Britton \& Rose)) }\end{array}$ & $\begin{array}{c}\text { Abacaxi } \\
\text { (Ananas comosus (L.) Merr) }\end{array}$ & $\begin{array}{c}\text { Cebola brava } \\
\text { (Hebranthus sylvaticus } \\
\text { Herb) }\end{array}$ \\
\hline Incó (Capparis yco Mart.) & $\begin{array}{c}\text { Juazeiro (Ziziphus joazeiro } \\
\text { Mart.) }\end{array}$ & Bananeira (Musa sp.) & \\
\hline $\begin{array}{l}\text { Licurizeiro (Syagrus coronata } \\
\text { (Mart.) Becc) }\end{array}$ & $\begin{array}{c}\text { Sisal (Agave sisalana Perrine } \\
\text { ex Engelm) }\end{array}$ & $\begin{array}{c}\text { Cajazeira (Spondias mombin } \\
\text { L.) }\end{array}$ & \\
\hline \multicolumn{4}{|l|}{$\begin{array}{c}\text { Mandacaru (Cereus jamacaru } \\
\text { DC.) }\end{array}$} \\
\hline \multicolumn{4}{|l|}{$\begin{array}{c}\text { Mandioca brava (Maniohot } \\
\text { utilíssima Pohl) }\end{array}$} \\
\hline \multicolumn{4}{|l|}{$\begin{array}{l}\text { Palma (Opuntia cochenillifera } \\
\text { (L) Mill.) }\end{array}$} \\
\hline \multicolumn{4}{|l|}{$\begin{array}{c}\text { Quixabeira (Sideroxylon } \\
\text { obtusifolium (Roem. \& Schult.) } \\
\text { T.D.Penn.) }\end{array}$} \\
\hline $\begin{array}{l}\text { Xique-Xique (Pilosocereus } \\
\text { gounellei (F.A.C. Weber ex K. } \\
\text { Schum.) Byles \& G.D. Rowley }\end{array}$ & & & \\
\hline
\end{tabular}

Quadro 2: Relação das plantas escolhidas pelos alunos do $8^{\circ}$ ano da EFA-Valente.

Essa associação das plantas como meio de sobrevivência na região, bem como sua utilização pelas famílias é enfatizada no Eixo Gerador do $7^{\circ}$ ano que aborda os fatores de produção e sustentabilidade, através de análise e observação das atividades e serviços desenvolvidas nas suas comunidades e continuadas no $8^{\circ}$ ano através do Eixo Gerador: Convivência no semiárido, que tem como objetivo iniciar os alternantes no campo do estágio, incentivando a reflexão e ação sobre as descobertas no campo do trabalho para a turma, que já está encaminhando-se para a formação do jovem agricultor e possuem um forte sentimento de pertencimento ao campo e reconhecem-se como parte integrante da natureza (EFA VALENTE, 2015). Através das categorias estabelecidas pelas duas turmas, é notória a importância dos conhecimentos prévios dos estudantes sobre a biodiversidade para o ensino de sistemas de classificação biológica. Baptista (2007) afirma que o ensino de ciências pautado na supervalorização dos saberes científicos em relação dos saberes tradicionais, pode direcionar os (as) estudantes a conflitos entre essas duas explicações. Dessa forma, nossa pesquisa buscou promover o diálogo entre esses saberes para que os (as) alternantes pudessem agregar informações ao conhecimento que eles (as) já possuem.

$\mathrm{O}$ site da EFA está organizado com páginas que apresentam a escola, os trabalhos produzido a partir da parceria com a universidade, para o herbário digital organizamos as espécies vegetais trabalhadas na oficina, bem como as que já estavam na versão anterior do site por grupos funcionais: plantas medicinais, ornamentais, utilizadas na alimentação humana, utilizadas na alimentação animal e plantas da Caatinga. A classificação é um método usado para organizar conhecimentos e agrupar seres afins, facilitando a atividade científica. Atividades como o herbário escolar proporcionam uma abordagem ativa no ensino de botânica, aplicando conhecimentos na prática (FAGUNDES; GONZALES, 2009). O site conta ainda com a divulgação de 
outras oficinas que abordam estratégias para o ensino de botânica buscando a valorização de conhecimentos tradicionais.

\section{CONSIDERAÇÕES FINAIS}

Levando-se em consideração a relação entre conhecimentos tradicionais, plantas da caatinga e educação do campo, trabalhar com os alunos do ensino fundamental temas como biodiversidade e classificação biológica, envolvendo os conhecimentos prévios e sua vivencia em uma comunidade rural, se faz de grande importância, tanto para aprimorar o conhecimento científico como criar laços com a comunidade em que eles se encontram. A reorganização do Herbário Digital da EFA trouxe para a escola uma excelente ferramenta de divulgação dos trabalhos desenvolvidos na escola. Assim, a proposta metodológica desenvolvida nessa pesquisa nos mostra que apesar das dificuldades encontradas em promover um ensino de ciências que abarque a multiculturalidade da sala de aula, é possível pensar em estratégias que se aproximem do cotidiano dos alunos, possibilitando um ensino contextualizado de ciências, ampliando o diálogo de saberes e o fortalecimento do sentimento de pertencimento entre os estudantes e sua comunidade.

\section{REFERÊNCIAS}

BARDIN, L. Análise de conteúdo. São Paulo: Edições 70, 2004, 229 p.

BARBIER, R. A pesquisa-ação. Brasília: Plano Editora, 2002.

BAPTISTA, G. C. Santos. Importância da demarcação de saberes no ensino de ciências para sociedades tradicionais. Ciência \& Educação, v. 16, n. 3, p. 679-694, 2010.

Disponível em: http://www.scielo.br/pdf/ciedu/v16n3/v16n3a12.pdf. Acesso em 13 de jun. de 2019.

EFA VALENTE. Projeto Político Pedagógico. 2015. Mimeo.

FAGUNDES, J. A.; GONZALES, C. E. F. Herbário escolar: suas contribuições ao estudo da Botânica no Ensino Médio. 34 p. 2009. Disponivel em:

http://www.diaadiaeducacao.pr.gov.br/portals/pde/arquivos/1675-8.pdf. Acesso em: 01. Ago. de 2019

LIMA, L. da A.; FREIXO, A. A. Saberes e Sabores do Campo: Relações entre

Conhecimentos Científicos e Tradicionais Numa Escola Família Agrícola do Sertão da

Bahia. Revista Metáfora Educacional, n. 13, p. 21-35, 2012. Disponível em:

https://dialnet.unirioja.es/servlet/articulo?codigo=4153132. Disponível em: 20 . jul. 2019.

OLIVEIRA, J. F. C.; FREIXO, A. A. Contribuições De Um Herbário Escolar Para O

Ensino De Ciências No Contexto Da Educação Do Campo. Ciência \&

Desenvolvimento-Revista Eletrônica da FAINOR, v. 12, n. 2, 2019.

TEIXEIRA, A. M. F.; FREIXO, A. A. Educação do campo e memória de velhos: navegando entre o passado e o presente. Revista Contrapontos, v. 11, n. 1, p. 14-23, 2011. Disponível em: http://www6.univali.br/seer/index.php/rc/article/view/2261.

Acesso em:01. Ago. de 2019 